\title{
Effect of Progressive Resistance Training and Plyometric Training Programme on Explosive Strength, Cardiovascular Endurance and Body Composition among Teen Age Boys
}

\author{
Mr.Sinikumar*, Dr. Aurther Daniel**, Dr.K.Sreedhar*** \\ *PhD Scholar, Department of Physical Education and Sports, \\ Manonmaniam Sundaranar University, Tirunelveli, \\ ** Director of Physical Education, Scot Christian College, Nagercoil. \\ *** Associate Professor, Department of Physical Education and Sports Sciences, \\ Annamalai University, Annamalainagar-608002, Tamilnadu, India.
}

\begin{abstract}
The purpose of the study was to find out the effect of progressive resistance training and Plyometric training on explosive strength, cardiovascular endurance and body composition among teen age boys. To achieve this purpose, 60 male students were randomly selected. The age of the subjects were ranged from 15 to 18 years. The subjects were further classified at random into three equal groups of 20 subjects each. Group - I acted as control, group - II underwent resistance training for three days per week and group - III underwent Plyometric training for three days per week for twelve weeks. The selected criterion variables namely speed, muscular endurance and body composition were assessed before and after the training period. The collected data were statistically analyzed by using Analysis of Covariance (ANCOVA). When the F ratio of the adjusted post test mean was found to be significant, Scheffe's post hoc test was employed to find out the paired mean difference. All the data were analyzed using SPSS statistical package. From the results of the study it was found that there was a significant improvement on explosive strength, cardiovascular endurance, and significant reduction in body weight, BMI percent body fat among the experimental groups when compared with the control group
\end{abstract}

Keywords: Resistance Training, Plyometric Training, Explosive Strength, Cardiovascular Endurance, Body Composition

\section{INTRODUCTION}

The training is viewed as providing stimuli that promotes specific and varied adaptations depending on the type of intensity and duration of exercise performed for every sport. Resistance training also known as strength, or weight training, has become one of the most popular forms of exercise both for enhancing an individual's physical fitness and for conditioning athletes. The terms strength, weight and resistance training have all been used to describe a type of exercise that requires the body's musculature to move (or attempt to move) against an opposing force. Usually presented by some type of equipment. The terms resistance and strength training encompass a wide range of training modalities, including plyometrics and will refer only to normal resistance training using free weights or weight machines. The increasing number of health club, high school and college resistance training facilities attests to popularity of this form of physical conditioning. Individuals who participate on a resistance training program expect the program to produce certain benefits, such as increased strength, increased muscle size, improved sports performance, increased fat-free mass and decreased body fat. Plyometrics are training techniques used by athletes in all types of sports to increase strength and explosiveness (Chu, 1998). Plyometric movements, in which a muscle is loaded and then contracted in rapid sequence, use the strength, elasticity and innervations of muscle and surrounding tissues to jump higher, run faster, throw farther, or hit harder, depending on the desired training goal. Plyometrics is used to increase the speed or force of muscular contractions, providing explosiveness for a variety of sport-specific activities. Plyometrics has been shown across the literature to be beneficial to a variety of athletes. Plyometrics consists of a rapid stretching of a muscle (eccentric action) immediately followed by a concentric or shortening action of the same muscle and connective 
tissue (Baechle and Earle, 2000). The stored elastic energy within the muscle is used to produce more force than can be provided by a concentric action alone (Asmussen and Bonde-Peterson, 1974; Cavagna, 1977; Komi, 1992; Miller, et al., 2002; Pfeiffer, 1999; Wathen, 1993). Researchers have shown that plyometric training, when used with a periodized strength-training program, can contribute to improvements in vertical jump performance, acceleration, leg strength, muscular power, increased joint awareness, and overall proprioception (Adams, et al., 1992; Anderst et al., 1994; Bebi et al., 1987;Bobbert, 1990; Brown et al., 1986; Clutch et al., 1983; Harrison and Gaffney, 2001; Hennessy and Kilty, 2001; Hewett et al., 1996; Holcomb et al.,1996; Miller et al., 2002; Paasuke et al., 2001; Potteiger et al., 1999; Wilson et al., 1993). Plyometric training bridges the gap between strength and speed. In children and adolescents, it is well-established that training-induced gains in strength and power are indeed possible following participation in a resistance training program (Faigenbaum et al., 1996). More recent observations suggest that plyometric training may also be safe and effective for children and adolescents provided that age appropriate training guidelines are followed (Chu et al., 2006). Lean body weight and fat weight are the two component systems of the muscle, bone, internal organs and connective tissues in the body. Fat weight usually is expressed relative to the total body weight of the individuals. Excessive body fat leads to obesity and enhances the risk of developing coronary heart diseases. It is important to realize that individuals may be overweight even through they do not appear to be overweight. This may be caused by a lack of physical activity (Heyward,1984).There is very little literature available on the effect of resistance training and plyometric training on speed, muscular endurance among school students and hence this study was taken

\section{METHODOLOGY}

The purpose of the study was to find out the effect of resistance training and plyometric training programme on explosive strength, cardiovascular endurance and body composition among teen age boys. To achieve the purpose of this study, sixty students studying in St.Francis. Higher Secondary School, Vavarai were selected as subjects. The selected subject's age group ranged from fifteen to eighteen years. The subjects were randomly divided into three groups namely, control group (Control), resistance training group (Experimental-I) and plyometric training group (Experimental-II). Experimental-I underwent resistance training, Experimental-II underwent plyometric training and control group did not participate in any training programme other than their regular activities according to their curriculum. The experimental period was of twelve weeks. The requirements of the experimental procedures, testing as well as exercise schedules were explained to them so as to avoid any ambiguity of the effort required on their part and prior to the administration of the study, the investigator got the individual consent from each subject. The experimental group II underwent plyometric training for the period of twelve weeks, three alternative days per week (Monday, Wednesday and Friday). The subjects of the experimental group II performed the following selected exercises namely - Side to side ankle hops, Standing jump and reach, Front cone hops, Standing long jump, Lateral jump over barrier, Double leg hops, Lateral cone hops, Diagonal cone hops, Single leg bounding, Lateral jump single leg, Hexagon drill, Cone hops with 180 degree turn, Cone hops with change of direction sprint $4 \times 6$. The plyometric training group participated in a 12-week training program performing a variety of plyometric exercises designed for both upper and the lower extremities, while the control group did not participate in any plyometric exercises. The resistance training group trained three non-alternative days in a week for 12 weeks. The subjects underwent a beginner program for two weeks with three sessions per week. The duration of the sessions was 60 min. The exercises included total and segmental movements of upper limps and lower limbs. In the second section the resistance training group underwent resistance training program for ten weeks. The 1RM for each exercise was progressively increased from 50\% to $90 \%$ 1RM from the third week through twelth week. The subjects performed a brief warm up consisting of static stretching before and after the training sessions. The training consisted of the following exercises performed thrice a week with gradual increase in sets and repetitions and decrease in recovery period - squats, front squats, stiff- legged dead lifts, bench press, upright rows, back press, front press, barbell curls and, dumbbell side bends. During the training, all subjects were under direct supervision and were instructed on how to perform each exercise. The subjects were assessed on selected criterion variables namely explosive strength, cardiovascular endurance, bodyweight, BMI and percent body fat before 
Effect of Progressive Resistance Training and Plyometric Training Programme on Explosive Strength, Cardiovascular Endurance and Body Composition among Teen Age Boys

and after the training period. The selected variables were measured by using standard testing procedures.

The data collected from experimental group and control groups prior to and after completion of the training period on selected variables were statistically examined for significant differences if any, by applying analysis of covariance (ANCOVA). As all the three groups were selected from the same population and no attempt were made to equate the groups on the selected dependent variables or any other common variables, initial differences may exist, and there is a possibility of affecting the posttest mean. For eliminating any possible influence of pre test means the adjusted posttest means of experimental group and control groups were tested for significance by using ANCOVA. When the F ratio of the adjusted post test mean was found to be significant, Scheffe's post hoc test was employed to find out the paired mean difference. All the data were analyzed using SPSS statistical package. The level of confidence was fixed at 0.05 level of significance as the number of subjects was limited and also as the selected variables might fluctuate due to various extraneous factors.

\section{RESULTS AND DISCUSSION}

Table1. Analysis of Covariance for the Selected Variables Among Experimental Groups \& Control Group

\begin{tabular}{|c|c|c|c|c|c|}
\hline \multirow{4}{*}{ BODY WEIGHT } & & $\begin{array}{l}\text { Control } \\
\text { Group }\end{array}$ & $\begin{array}{l}\text { Experimental } \\
\text { Group-i }\end{array}$ & $\begin{array}{l}\text { Experimental } \\
\text { Group-ii }\end{array}$ & F-Ratio \\
\hline & PRE TEST & $60.70(4.91)$ & $59.95(5.45)$ & $59.50(5.65)$ & 0.25 \\
\hline & POST TEST & $60.70(4.68)$ & $58.55(4.74)$ & $57.35(5.59)$ & 2.28 \\
\hline & AD PO TEST & 60.15 & 58.64 & 57.82 & $7.75^{*}$ \\
\hline \multirow{3}{*}{ BMI } & PRE TEST & $23.40(1.71)$ & $22.71(2.27)$ & $23.01(2.29)$ & 0.52 \\
\hline & POST TEST & $23.40(1.71)$ & $22.18(1.99)$ & $22.17(2.08)$ & 2.69 \\
\hline & AD PO TEST & 23.10 & 22.46 & 22.20 & $7.85^{*}$ \\
\hline \multirow{3}{*}{$\begin{array}{c}\text { PERCENT BODY } \\
\text { FAT }\end{array}$} & PRE TEST & $18.88(4.70)$ & $19.01(4.27)$ & $19.60(4.42)$ & 0.15 \\
\hline & POST TEST & $17.90(4.62)$ & $16.51(3.65)$ & $17.27(3.64)$ & 0.61 \\
\hline & AD PO TEST & 18.15 & 16.64 & 16.88 & $33.24 *$ \\
\hline \multirow{3}{*}{$\begin{array}{l}\text { EXPLOSIVE } \\
\text { STRENGTH }\end{array}$} & PRE TEST & $42.90(2.59)$ & $42.70(2.27)$ & $42.45(2.11)$ & 0.19 \\
\hline & POST TEST & $43.05(2.72)$ & $49.45(2.24)$ & $53.20(2.09)$ & $94.10^{*}$ \\
\hline & AD PO TEST & 42.84 & 49.43 & 53.43 & $1147 *$ \\
\hline \multirow{3}{*}{$\begin{array}{c}\text { CAR VASCULAR } \\
\text { ENDURANCE }\end{array}$} & PRE TEST & $1811.5(68.85)$ & $1815.5(60.65)$ & 1789.99(71.5) & 0.37 \\
\hline & POST TEST & $1818(77.64)$ & $1907.5(87.53)$ & $1994.5(151.3)$ & $12.78^{*}$ \\
\hline & AD PO TEST & 1814.62 & 1899.85 & 2005.53 & $25.28 *$ \\
\hline
\end{tabular}

Table2. The Pre and Post Test Means of Experimental Groups and Control Group with Percentage of Gain

\begin{tabular}{|c|l|c|c|c|c|}
\hline \multirow{2}{*}{ VARIABLE } & \multicolumn{1}{|c|}{ GROUPS } & Pre Test & Post Test & Gain & $\begin{array}{c}\text { Percentage } \\
\text { of } \\
\text { Gain }\end{array}$ \\
\hline \multirow{3}{*}{ BODY WEIGHT } & Control & $60.70(4.91)$ & $60.70(4.68)$ & 0.00 & $0.00 \rightarrow$ \\
\cline { 2 - 6 } & Experimental-I & $59.95(5.45)$ & $58.55(4.74)$ & $1.40 \downarrow$ & $2.34 \% \downarrow$ \\
\cline { 2 - 6 } & Experimental-II & $59.50(5.95)$ & $57.35(5.59)$ & $2.15 \downarrow$ & $3.61 \% \downarrow$ \\
\hline \multirow{3}{*}{ BMI } & Control & $23.40(1.71)$ & $23.40(1.72)$ & 0.00 & $0.00 \rightarrow$ \\
\cline { 2 - 6 } & Experimental-I & $22.71(2.27)$ & $22.18(1.99)$ & $0.53 \downarrow$ & $2.33 \% \downarrow$ \\
\cline { 2 - 6 } $\begin{array}{c}\text { PERCENT } \\
\text { BODY FAT }\end{array}$ & Experimental-II & $59.50(5.95)$ & $57.35(5.59)$ & $0.84 \downarrow$ & $3.60 \% \downarrow$ \\
\cline { 2 - 6 } & Experimental-I & $18.88(4.70)$ & $17.90(4.62)$ & $0.98 \downarrow$ & $5.2 \% \downarrow$ \\
\cline { 2 - 6 } $\begin{array}{c}\text { EXPLOSIVE } \\
\text { STRENGTH }\end{array}$ & Experimental-II & $19.60(4.42)$ & $17.27(5.59)$ & $2.33 \downarrow$ & $11.89 \% \downarrow$ \\
\cline { 2 - 6 } & Control & $42.90(2.59)$ & $43.05(2.72)$ & $0.15 \uparrow$ & $0.35 \% \uparrow$ \\
\cline { 2 - 6 } & Experimental-I & $42.70(2.27)$ & $49.45(2.24)$ & $6.75 \uparrow$ & $15.81 \% \uparrow$ \\
\hline \multirow{2}{*}{$\begin{array}{c}\text { VASCRR } \\
\text { ENDURANCE }\end{array}$} & Control & $1811.5(68.85)$ & $1818(77.64)$ & $6.50 \uparrow$ & $0.36 \% \uparrow$ \\
\cline { 2 - 6 } & Experimental-I & $1815.5(60.65)$ & $1907.5(87.53)$ & $92.00 \uparrow$ & $5.07 \% \uparrow$ \\
\cline { 2 - 6 } & Experimental-II & $1789(71.50)$ & $1994.5(151.29)$ & $2.5 .50 \uparrow$ & $12.22 \% \uparrow$ \\
\hline
\end{tabular}


Table3. The Scheffe's Test for Differences between the Adjusted Post Test Paired Means

\begin{tabular}{|c|c|c|c|c|c|}
\hline \multirow[t]{2}{*}{ VARIABLE } & \multicolumn{3}{|c|}{ Adjusted Post test means } & \multirow{2}{*}{$\begin{array}{c}\text { Mean } \\
\text { Difference }\end{array}$} & \multirow{2}{*}{$\begin{array}{l}\text { Confidence } \\
\text { Interval }\end{array}$} \\
\hline & $\begin{array}{l}\text { Control } \\
\text { group }\end{array}$ & $\begin{array}{l}\text { Resistance } \\
\text { training } \\
\text { group }\end{array}$ & $\begin{array}{l}\text { Plyometric } \\
\text { training } \\
\text { group }\end{array}$ & & \\
\hline \multirow{3}{*}{$\begin{array}{c}\text { BODY } \\
\text { WEIGHT }\end{array}$} & 60.15 & 58.64 & & 1.51 & \multirow[t]{3}{*}{1.52} \\
\hline & 60.15 & & 57.82 & $2.33 *$ & \\
\hline & & 58.64 & 57.82 & 0.82 & \\
\hline \multirow{3}{*}{ BMI } & 23.10 & 22.46 & & $0.64 *$ & \multirow[t]{3}{*}{0.59} \\
\hline & 23.10 & & 22.20 & $0.90 *$ & \\
\hline & & 22.46 & 22.20 & 0.26 & \\
\hline \multirow{3}{*}{$\begin{array}{l}\text { PERCENT } \\
\text { BODY FAT }\end{array}$} & 18.15 & 16.64 & & $1.51^{*}$ & \multirow[t]{3}{*}{0.50} \\
\hline & 18.15 & & 16.88 & $1.27 *$ & \\
\hline & & 16.64 & 16.88 & 0.24 & \\
\hline \multirow{3}{*}{$\begin{array}{l}\text { EXPLOSIVE } \\
\text { STRENGTH }\end{array}$} & 8.18 & 7.96 & & $0.22 *$ & \multirow[t]{3}{*}{0.08} \\
\hline & 8.18 & & 7.80 & $0.38 *$ & \\
\hline & & 7.96 & 7.80 & $0.16 *$ & \\
\hline \multirow{3}{*}{$\begin{array}{c}\text { CAR } \\
\text { VASCULAR } \\
\text { ENDURANCE } \\
\end{array}$} & 27.71 & 37.68 & & $9.97 *$ & \multirow[t]{3}{*}{0.42} \\
\hline & 27.71 & & 34.31 & $6.60 *$ & \\
\hline & & 37.68 & 34.31 & $3.37 *$ & \\
\hline
\end{tabular}

The pre test means and post test means of the body weight among control group $(60.70 \pm 4.97$ vs 60.70 \pm 4.68 ) shows no change, the pre test means and post test means of body weight among resistance training group $(59.95 \pm 5.45$ vs $58.55 \pm 4.74)$ shows a decrease of $1.40 \mathrm{~kg}(2.34 \%)$ and the pre test means and post test means of body weight among plyometric training group (59.50 \pm 5.95 vs $57.35 \pm$ $5.59)$ shows a decrease of $2.15 \mathrm{~kg}(3.61 \%)$. Furthermore when the adjusted post test means of resistance training (58.64) plyometric training (57.82) and control groups (60.15) were analyzed by means of analysis of covariance, the obtained results indicate an significant difference among the groups. ( $p>0.05)$. The post hoc result of the study shows that both resistance and plyometric trainings have reduced body weight when compared with control group. Further the results indicated that there was no significant change in body weight between the plyometric training group and the resistance training group.

The pre test means and post test means of the BMI among control group shows no change, the pre test means and post test means of BMI among resistance training group $(22.71 \pm 2.71$ vs $22.18 \pm 1.99)$ shows a decrease of $0.53 \mathrm{~kg} / \mathrm{m}^{2}(2.33 \%)$ and the pre test means and post test means of BMI among plyometric training $(23.01 \pm 2.29$ vs $22.17 \pm 2.08)$ shows a decrease of $0.84 \mathrm{~kg} / \mathrm{m}^{2}(3.65 \%)$. Furthermore when the adjusted post test means of resistance training group (22.46) plyometric training (22.20) and control groups (23.10) were analyzed by means of analysis of covariance, the obtained results indicate a significant difference among the groups. $(\mathrm{p}>0.05)$. The post hoc results of the study show that both resistance and plyometric trainings have reduced BMI when compared with control group. Further the results indicated that there was no significant change in BMI between the plyometric training group and the resistance training group.

The pre test means and post test means of the percent body fat among control group (18.88 $\pm 4.70 \mathrm{vs}$ $17.90 \pm 4.62$ ) shows a decrease of $0.98(5.2 \%)$, the pre test means and post test means of percent body fat among resistance training group $(19.01 \pm 4.27 \mathrm{vs} 16.51 \pm 3.65)$ shows a decrease of 2.50 ( $13.16 \%)$ and the pre test means and post test means of percent body fat among plyometric training group $(19.60 \pm 4.42$ vs $17.27 \pm 3.64)$ shows a decrease of $2.33(11.89 \%)$. Furthermore when the adjusted post test means of resistance training (16.64) plyometric training (16.88) and control groups (18.15) were analysed by means of analysis of covariance, the obtained results indicate an significant difference among the groups. $(\mathrm{p}>0.05)$. The post hoc results of the study shows that both resistance and plyometric trainings have reduced percent body fat when compared with control group. Further the results indicated that there was no significant change in percent body fat between the plyometric training group and the resistance training group. The possible reason may be due to a significant decrease in body weight and also due to the fact that training program more than 6 weeks results in fat reduction and increase in fat free mass.

The pre test means and post test means of the cardio vascular endurance among control group $(1811.50 \pm 68.85 \mathrm{vs} 1818.00 \pm 77.64)$ shows an increase of $6.50 \mathrm{mts}(0.36 \%)$, the pre test means and 
post test means of cardio vascular endurance among resistance training group (1815.50 $\pm 60.65 \mathrm{vs}$ $1907.50 \pm 87.53)$ shows an increase of $92.00 \mathrm{mts}(5.07 \%)$ and the pre test means and post test means of cardio vascular endurance among plyometric training group (1789.00 \pm 71.50 vs $1994.50 \pm 151.29)$ shows an increase of $205.50 \mathrm{mts}(12.22 \%)$. Furthermore when the adjusted post test means of resistance training (1899.85), plyometric training (2005.53) and control groups (1814.62) were analyzed by means of analysis of covariance, the obtained results indicate an significant difference among the groups. $(\mathrm{p}>0.05)$. The post hoc results of the study shows that both resistance and plyometric trainings have increased cardio vascular endurance when compared with control group. Further the results indicated that there was a significant increase in cardio vascular endurance in the plyometric training group than the resistance training group.

The pre test means and post test means of the explosive strength among control group (42.90 \pm 2.59 vs $43.05 \pm 2.72)$ shows an increase of $0.15 \mathrm{cms}(0.35 \%)$, the pre test means and post test means of explosive strength among resistance training group $(42.70 \pm 2.27$ vs $49.45 \pm 2.24)$ shows an increase of $6.75 \mathrm{cms}(15.81 \%)$ and the pre test means and post test means of explosive strength among plyometric training group $(42.45 \pm 2.11$ vs $53.20 \pm 2.09)$ shows an increase of $10.75 \mathrm{cms}(25.32 \%)$. Furthermore when the adjusted post test means of resistance training (49.43) plyometric training (53.43) and control groups (42.84) were analyzed by means of analysis of covariance, the obtained results indicate an significant difference among the groups. ( $p>0.05)$. The post hoc results of the study shows that both resistance and plyometric trainings have increased explosive strength when compared with control group. Further the results indicated that there was a significant increase in explosive strength in the plyometric training group than the resistance training group. Marked evidence indicates that regular participation in a resistance training program or a plyometric training program can improve measures of strength and power in adults (Chu,1998; Fleck and Kraemer,2004) and there is substantial evidence available to suggest that plyometric training improved jumping performance in different populations (Matavulj et al., 2001; Kotzamanidis, 2006; Ebben and Watts, 1998; Adams et al., 1992; Leubbers et al., 2003). The effect of resistance training on vertical jump has been investigated extensively with consistently positive findings (Baker, 1996; Fatorous et al., 2000; Ebben \& Watts, 1998; Adams et al., 1992). Plyometrics has been shown to be more effective than resistance training at improving vertical jump performance (Leubbers et al., 2003; Newton et al., 1999; Fatorous et al., 2000; Adams et al., 1992).

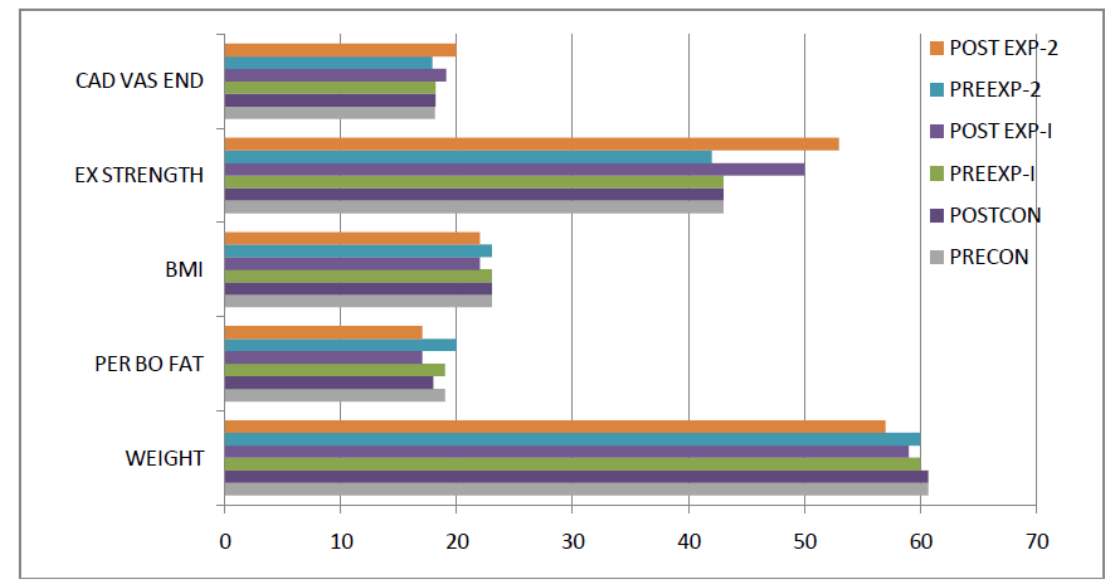

\section{Conclusion}

The plyometric training program has resulted in a significant increase in explosive strength, cardiovascular endurance, Body weight, BMI and percent body fat among teenage boys.

\section{REFERENCES}

Adams, K., O'Shea, J.P., O'Shea, K.L. and Climstein, M. (1992) The effects of six weeksofsquat, plyometrics, and squat plyometric training on power production. Journal of Applied Sports Science Research 6, 36-41.

Anderst, W.J., Eksten, F. and Koceja, D.M. (1994) Effects of plyometric and explosive resistance training on lower body power. Medicine and Science in Sport and Exercise 26, S31.

Asmussen, E. and Bonde-Peterson, F. (1974) Apparent efficiency and storage of elastic energy in human muscles during exercise. Acta Physiologica Scandinavica 92, 537-545. 
Baechle, T.R. and Earle, R.W. (2000) Essentials of strength training and conditioning. 2nd edition.Champaign, IL: National Strength and Conditioning Association

Bebi, J., Cresswell, A., Engel, T. and Nicoi, S. (1987) Increase in jumping height associated with maximal effort vertical depth jumps. Research Quarterly for Exercise and Sport 58, 11-15.

Bobbert, M. (1990) Drop jumping as a training method for jumping ability. Sports Medicine 9, 7-22.

Brown, M.E., Mayhew, J.L. and Boleach, L.W. (1986) Effects of plyometric training on vertical jump performance in high school basketball players. Journal of Sports Medicine and Physical Fitness $26,1-4$.

Cavagna, G. (1977) Storage and utilization of elastic energy in skeletal muscle. Exercise and Sports Sciences Reviews 5, 89-129.

Chu, D.; Faigenbaum, A.; Falkel, J. (2006) Progressive plyometrics for kids. Healthy Learning, Champaign, IL: Human Kinetics

Chu, D.A. (1998) Jumping into plyometrics. Champaign, IL: Human Kinetics.

Clutch, D., Wilton, B., McGown, M. and Byrce, G.R.(1983) The effect of depth jumps and weight training on leg strength and vertical jump. Research Quarterly for Exercise and Sport 54, 5-10.

Faigenbaum D.A; James E.M.; Fred B.K., William T.; NicholaS A.R.; Jie Kang; Jay R.H.Effects of a short-term plyometric and resistance training program on fitness performance in boys age 12 to 15 years, Journal of Sports Sciences and Medicine. v. 6, p. 519-525, 2007.

Harrison, A.J. and Gaffney, S. (2001) Motor development and gender effects on stretch-shortening cycle performance. Journal of Science and Medicine in Sport 4, 406-415.

Hennessy, L. and Kilty, J. (2001) Relationship of the stretch-shortening cycle to spring performance in trained female athletes. Journal of Strength and Conditioning Research 15, 326-331.

Hewett, T.E., Stroupe, A.L., Nance, T.A. and Noyes, F.R.(1996) Plyometric training in female athletes. Decreased impact forces and increased hamstring torques. American Journal of Sports Medicine 24,765-773.

Holcomb, W.R., Lander, J.E., Rutland, R.M. and Wilson,G.D. (1996) A biomechanical analysis of the vertical jump and three modified plyometric depth jumps. Journal of Strength and Conditioning Research 10,, 83-88.

Komi, P.V. (1992) The stretch-shortening cycle. In: Strength and power in sport. Boston, Mass: Blackwell Scientific. 169-179.

Miller, M.G., Berry, D.C., Bullard, S. and Gilders, R. (2002) Comparisons of land-based and aquaticbased plyometric programs during an 8-week training period. Journal of Sports Rehabilitation 1, 269-283.

Paasuke, M., Ereline, J. and Gapeyeva, H. (2001) Knee extensor muscle strength and vertical jumping performance characteristics in pre and post- pubertal boys. Pediatric Exercise Science 13, 60- 69.

Pfeiffer, R. (1999) Plyometrics in sports injury rehabilitation. Athletic Therapy Today 4(3), 5.

Piper, T.J. and Erdmann, L.D. (1998) A 4 step plyometric rogram. Strength and Conditioning 20(6), 72-73.

Potteiger, J.A., Lockwood, R.H., Haub, M.D., Dolezal, B.A., Alumzaini, K.S., Schroeder, J.M. and Zebas, C.J. (1999) Muscle power and fiber characteristic following 8 weeks of plyometric training. Journal of Strength and Conditioning Research 13, 275- 279.

Wathen, D. (1993) Literature review: explosive/plyometric exercises. Strength and Conditioning 15(3), 17-19.

Wilson, G.J., Newton, R.U., Murphy, A.J. and Humphries, B.J. (1993) the optimal training load for the development of dynamic athletic performance. Medicine and Science in Sports and Exercise $25,1279-1286$. 